\title{
IN HOUSE TRAINING PADA PERAWAT PK I-PK IV TERHADAP PENGETAHUAN TENTANG MANAJEMEN NYERI
}

\author{
Ernawaty Siagian, Deasy Lolyta Angeline \\ Rumah Sakit Advent Bandar Lampung \\ Email: ernawatysiagian74@yahoo.com
}

\begin{abstract}
Pain is a subjective response to physical and psychological stressors. All individuals experience pain in several places during their lives. The important role of nurses in pain management is to assess, document, decide on pain management that must be given and monitor the development of pain management that has been given. The purpose of this study was to determine the level of nurse knowledge about pain management. The research method is pre experimental one group pretest-posttest design with an accidental technique approach involving 89 nurses with career paths including IV I-PK PK. The variables studied were to determine nurses' knowledge about pain management with pretest and posttest questionnaires. The results obtained on nurses before the seminar on PK I 61\% and after the seminar 70\%, before the seminar on PK II was $63 \%$ and after the seminar $76 \%$, before the seminar on PK III was $60 \%$ and after the seminar $73 \%$, before the seminar on PK IV was $57 \%$ and after the seminar $78 \%$. Paired T-test results there were significant differences in nurses' knowledge about pain management before and after In-House Training on nurses PK I-IV $p$-value $0,000<0.05$ By providing In House Training to nurses can improve the knowledge of nurses in pain management.
\end{abstract}

Keywords: In House Training, Pain Management, Knowledge

\begin{abstract}
ABSTRAK
Nyeri adalah respon subjektif terhadap stresor fisik dan psikologis. Semua individu mengalami nyeri pada beberapa tempat selama kehidupan mereka. Peranan penting perawat dalam manajemen nyeri adalah menilai, mendokumentasikan, memutuskan manajemen nyeri yang harus diberikan serta memantau perkembangan manajemen nyeri yang sudah diberikan. Tujuan penelitian untuk mengetahui tingkat pengetahuan perawat tentang manajemen nyeri. Metode penelitian yang digunakan adalah pre eksperimental one group pretest-posttest design dengan teknik Accidental Sampling melibatkan 89 perawat dengan jenjang karir PK I-PK IV. Variabel yang diteliti untuk mengetahui pengetahuan perawat tentang manajemen nyeri dengan kuesioner pretest dan posttest. Hasil yang didapat pada perawat sebelum seminar PK I 61\%, setelah seminar 70\%. Pada PK II 63\% dan setelah seminar 76\%. Pada PK III nilainya 60\% dan setelah seminar 73\%. Pada PK IV sebelum seminar 57\% dan setelah seminar 78\%. Hasil uji Paired T-test ada perbedaan yang signifikan terhadap pengetahuan perawat tentang manajemen nyeri sebelum dan sesudah In House Training pada perawat PK I-IV nilai p-value 0,000<0,05. Dengan memberikan In House Training kepada perawat dapat meningkatkan pengetahuan perawat dalam penatalaksanaan manajemen nyeri.
\end{abstract}

Kata kunci: In House Training, Manajemen nyeri, Pengetahuan 


\section{Pendahuluan}

Nyeri menurut IASP (International Assossiation for the Study of Pain) adalah pengalaman sensori dan emosional yang tidak menyenangkan akibat kerusakan jaringan yang aktual atau potensial atau yang cenderung merusak jaringan. Definisi keperawatan tentang nyeri adalah, apapun yang menyakitkan tubuh yang dikatakan individu yang mengalaminya, yang ada kapanpun individu mengatakannya (Brunner \& Suddarth, 2010). Nyeri adalah persepsi dalam kondisi sadar yang dihasilkan dari stres lingkungan, dan muncul jika individu tidak berhasil untuk menghindar dari situasi yang berbahaya dan terjadi kerusakan. Nyeri merupakan fenomena multidimensional sehingga sulit untuk didefinisikan. Nyeri merupakan pengalaman personal dan subjektif, dan tidak ada dua individu yang merasakan nyeri dalam pola yang identik. Nyeri dapat didefinisikan dengan berbagai cara. Nyeri biasanya dikaitkan dengan beberapa jenis kerusakan jaringan, yang merupakan tanda peringatan, namun pengalaman nyeri lebih dari itu. Kerusakan (Black \& Hawks, 2014). Menurut World Health Organization (WHO), dari 26.000 perawat primer di lima benua, 22\% melaporkan adanya nyeri persisten lebih dari setahun (Kuntono, 2011). Berdasarkan American Pain Society (APS) 50 juta warga Amerika lumpuh sebagian atau total karena nyeri, dan $45 \%$ dari warga Amerika membutuhkan perawatan nyeri yang persisten seumur hidup mereka. Kira-kira 50-80\% pasien di rumah sakit mengalami nyeri disamping keluhan lain yang menyebabkan pasien masuk rumah sakit (Ivan, 2013). Pasien dalam merespon terhadap nyeri yang dialaminya dengan cara berbeda-beda, misalnya berteriak, meringis, dan lain-lain. Di lebih dari separuh kasus, pasien laporkan tidak menerima manajemen rasa sakit yang memadai setelah prosedur mereka, yang menimbulkan kekhawatiran akan perkembangan rasa sakit kronis di telepon (Tenant \& Ciccone, 2016).

Oleh karena nyeri bersifat subjektif, maka perawat harus peka terhadap sensasi nyeri yang dialami pasien (Asmadi, 2008). Namun sayangnya belum banyak yang diketahui dan belum dikelola dengan baik, padahal perawat memiliki lebih banyak kesempatan dibandingkan tenaga kesehatan lain untuk membantu

Published by Faculty of Nursing | Universitas Klabat menghilangkan nyeri dan efeknya yang membahayakan (Brunner \& Studdarth, 2008). Menurut penelitian Elysabeth dkk (2015), masih ditemukannya intervensi keperawatan yang berdasarkan "kebiasaan". Perawat harus secara sistemastis menggunakan bukti-bukti terbaik yang aktual dalam membuat keputusan mengenai cara menangani pasien. Manajemen rasa nyeri dianggap sebagai bagian penting dari perawatan sehingga American Pain Society (2003) mengacu pada rasa nyeri sebagai "tanda vital kelima" untuk menekankan pentingnya manajemen nyeri yang efektif dan untuk meningkatkan kesadaran di kalangan profesional perawatan kesehatan untuk melakukan dokumentasi penilaian rasa nyeri. The Joint Commission (2001) menetapkan standar nyeri yang mengidentifikasi pemulihan nyeri sebagai hak pasien, serta mewajibkan fasilitas kesehatan mengimplementasikan prosedur khusus, dan pendidikan bagi penyedia layanan kesehatan, pengkajian dan manajemen nyeri (Brunner \& Suddarth, 2010).

Satu yang paling relevan bagi perawat adalah bahwa nyeri adalah "apapun yang dialami individu sebagai nyeri adalah nyeri dan benar terjadi, dan kapanpun individu mengatakan nyeri artinya benar adanya" (McCaffery, 1979, hlm,11). Definisi ini menunjukkan bahwa pasien adalah satu-satunya individu yang dapat mendefinisikan dan menjelaskan nyeri secara akurat yang mereka alami dan berfungsi sebagai dasar untuk pengkajian keperawatan dan asuhan keperawatan pasien terkait nyeri. Definisi ini mendukung nilai dan kepercayaan tentang nyeri yang memerlukan asuhan keperawatan holistic, termasuk: 1) Hanya individu sakit yang dapat merasakan nyeri; yaitu, nyeri memiliki arti yang personal.2) Jika pasien mengatakan bahwa ia mengalami nyeri, artinya pasien memang mengalami nyeri. Seluruh rasa nyeri itu nyata. 3) nyeri memiliki dimensi fisik, emosional, kognitif, sosiokultural, dan spiritual. 4) Nyeri mempengaruhi seluruh tubuh, biasanya secara negative. 5) Nyeri dapat berfungsi sebagai respons dan peringatan terhadap trauma actual atau potensial.

Association for Study of Pain (IASP) nyeri diartikan sebagai sensasi fisik atau kondisi emosi yang tidak diinginkan akibat rusaknya saraf atau jaringan di dalam tubuh seseorang (IASP, 2012; Sares, 2008). Nyeri terjadi bersama 
banyak proses penyakit atau bersamaan dengan beberapa pemeriksaan diagnostik maupun pengobatan lain (Brunner \& Suddarth, 2010). Nyeri dapat berasal dari setiap bagian dari tubuh manusia seperti kulit, otot, ligamen, sendi, tulang (nyeri nociceptive), jaringan terluka (nyeri inflamasi), saraf (nyeri neuropatik), organ internal (nyeri viseral) atau kombinasi dari jenis rasa sakit (nyeri campuran) (The British Pain Society, 2010). Di Indonesia, prevalensi individu yang menderita nyeri kronis khususnya muskuloskeletal sekitar 35,86\% total dari kunjungan pasien nyeri (PERDOSSI, 2007) dan sebagian besar yang mengalaminya adalah individu yang bekerja dan individu yang tinggal di kota besar (Badan Penelitian dan Pengembangan Kesehatan, 2013). Rentang usia individu yang menderita nyeri muskuloskeletal berada pada rentang usia 41 hingga 60 tahun atau usia produktif (Purba, 2006). Sistem saraf perifer memiliki dua jenis neuron, yaitu sensorik dan motorik. Pengalaman nyeri meliputi stimulasi sensorik dan persepsi. Stimulus nyeri dihasilkan dan dipindahkan melalui neuron sensorik, diterima di dalam system saraf pusat, dan direspons melalui neuron motorik. Koneksi atau sinaps terjadi dalam medulla spinalis dan kembali ke dalam otak, tempat interpretasi stimulus yang menimbulkan nyeri direspons. Stimulus nyeri dapat menyebabkan respons reflex segera yang menghasilkan kesadaran akan nyeri.

Nyeri akut memiliki tujuan yang jelas, yaitu memperingatkan cedera pada jaringan tubuh. Meskipun sering menyertai penyakit tertentu (seperti arthritis, migraine, atau kanker), nyeri kronis sering tidak memberikan tujuan yang bermanfaat, selain menjadi bagian dari masalah. Respon fisiologis terhadap nyeri meluas melebihi spasme otot dan respon fight or flight (peningkatan tekanan darah, frekuensi jantung, dan curah jantung, penurunan motilitas lambung dan usus), dan dapat mengalami efek yang merugikan pada kesehatan pasien. Nyeri mengganggu kuantitas dan kualitas tidur sehingga menyebabkan keletihan dan kemungkinan disorientasi. Metabolisme dan kebutuhan oksigen miokardium meningkat. Katabolisme (pemecahan jaringan tubuh) meningkat, dan penyembuhan terganggu. Fungsi imun tertekan, meningkatkan resiko infeksi (LeMone, Buerke \& Bauldoff, 2018)
Dalam meningkatkan kualitas hidup pasien nyeri kronis, diperlukan penanganan untuk mengurangi nyeri yang dirasakan. Ada berbagai bentuk manajemen nyeri untuk meningkatkan kualitas hidup pasien nyeri kronis yaitu farmakologi dan nonfarmakologi. Penggunaan farmakologi adalah metode yang paling umum digunakan dalam mengontrol rasa sakit akibat nyeri kronis sementara waktu. Walaupun begitu beberapa pasien dengan nyeri kronis menjadi tidak realistis lagi dengan obatan-obatan yang digunakannya dalam mengurangi nyeri kronis (Feinberg, Willer, Antonenko \& John, 2012). Penggunaan farmakologi dalam jangka waktu yang panjang, menyebabkan efek samping akibat penggunaan yang terlalu lama maupun adanya kombinasi dengan penggunaan obat lain. Hal ini cukup berbahaya bagi kesehatan pasien dan bisa mengancam hidup pasien itu sendiri (ACPA, 2016). Nonfarmakologi terdiri dari berbagai metode, seperti fisioterapi, kombinasi farmakologi dan fisioterapi serta Potensi yang melibatkan multidisiplin ilmu. Tujuan dari pemberian pengobatan maupun pendekatan manajemen nyeri kepada pasien nyeri kronis adalah untuk memulihkan fungsi dan meningkatkan kualitas hidup pasien nyeri kronis (Gordon dkk., 2010). Fisioterapi dilakukan untuk meningkatkan kekuatan otot, mempercepat proses penyembuhan, mengurangi rasa nyeri serta mengembalikan mobilitas dan ketahanan kerja otot paska cedera (Arovah, 2010). Terdapat berbagai macam jenis alat fisioterapi yang digunakan dan disesuaikan dengan kebutuhan pasien nyeri kronis seperti TENS, US, manual therapy, exercise therapy dan lain-lain. Namun terdapat beberapa resiko yang dapat terjadi pada pasien nyeri kronis ketika menjalani fisioterapi antara lain cedera pada saat latihan ataupun pada saat menerima terapi thermal dan electrotherapy, mengalami luka bakar pada thermotherapy atau frozen bite pada cryotherapy.

\section{Metode Penelitian}

Metode penelitian dalam penelitian ini adalah eksperimental dengan rancangan pre-post test dalam satu kelompok (One-group pre-post test design) dengan pendekatan teknik accidental sampling melibatkan 89 perawat dengan jenjang karir PK I-PK IV. Penelitian pre eksperimental 
diberikan test awal sebelum dibuat intervensi. Sesudah intervensi diberikan, test akhir dilakukan untuk melihat hasil dari intervensi. Populasi penelitian ini adalah perawat klinis (PK I - IV) yang berpengalaman kerja minimal 1 tahun, dengan usia 23-60 tahun dan berpendidikan DIII

- SI Ners, sampel dari penelitian ini adalah 89 orang. Instrumen yang digunakan adalah lembar kuesioner dimana di dapat data primer pada penelitian ini dengan menggunakan test hasil perlakuan (pre-test dan post test), yaitu lembar soal pretest (test awal sebelum mendapat perlakuan).

Lembar soal Post-test (tes akhir setelah mendapat perlakuan) Soal-soal yang diberikan diambil dari dari bank soal yang sudah teruji validitas dan reabilitasnya. Sumber pertanyaan diambil dari beberapa sumber yaitu: Dari Buku Uji Kompetensi Perawat \& Ners Indonesia 2017 dan Buku Ajar Keperawatan Medikal Bedah dengan pertanyaan terhadap pengetahuan perawat tentang manajemen nyeri. Uji statistic yang digunakan adalah Paired T-test. Setelah penyusunan test, maka setiap butir soal diberi skor. Skor yang diberikan untuk setiap jenjang kemampuan kognitif dengan hasil perhitungan yang akan diinterpretasikan dengan nilai presentasi persentasi yang didapatkan. 95100=sempurna; 90-95=istimewa; 84-89=baik sekali; 78-83=baik; 72-77=cukup baik; 6671=lebih dari cukup; 60-65=cukup.

\section{Hasil Penelitian}

Berdasarkan data yang diperoleh dari tabel 1 dapat dilihat nilai rata-rata Pre-test dan Post-test tingkat pengetahuan perawat PK I - PK IV tentang manajemen.

\section{Tabel 1}

Nilai Rata-rata Pre-test dan Post-Test Tingkat Pengetahuan Perawat PK I-IV dalam In House Training Manajemen Nyeri

\begin{tabular}{|c|c|c|c|c|c|c|}
\hline \multirow[t]{2}{*}{ No } & \multirow[t]{2}{*}{ PK } & \multirow[t]{2}{*}{ Responden } & \multicolumn{2}{|c|}{ Pre-Test } & \multicolumn{2}{|c|}{ Post-Test } \\
\hline & & & $\mathrm{F}$ & $\%$ & $\mathrm{~F}$ & $\%$ \\
\hline 1 & I & 28 & 153 & 61 & 176 & 70 \\
\hline 2 & II & 12 & 68 & 63 & 82 & 76 \\
\hline 3 & III & 30 & 162 & 60 & 197 & 73 \\
\hline \multirow[t]{2}{*}{4} & IV & 19 & 98 & 57 & 133 & 78 \\
\hline & Total & 89 & 481 & 60 & 588 & 73 \\
\hline
\end{tabular}

\section{Tabel 2}

Paired Samples Statistics

Paired Samples Statistics

\begin{tabular}{llllll} 
& & & & $\begin{array}{l}\text { Std. } \\
\text { Deviation }\end{array}$ & $\begin{array}{l}\text { Std. Error } \\
\text { Mean }\end{array}$ \\
\cline { 2 - 6 } Pair 1 & PRE & 60.1 & 89 & 18.884 & 2.002 \\
& POST & 73.47 & 89 & 23.007 & 2.439 \\
\hline
\end{tabular}


Tabel 2 dan 3 menunjukkan ada perbedaan yang signifikan antara pengetahuan perawat sebelum dan sesudah dilakukan in haouse training tentang manajemen nyeri, dengan menggunakan uji Paired t-test, $p$ value $=0,00<0,05$.

Tabel 3

Paired Samples Test

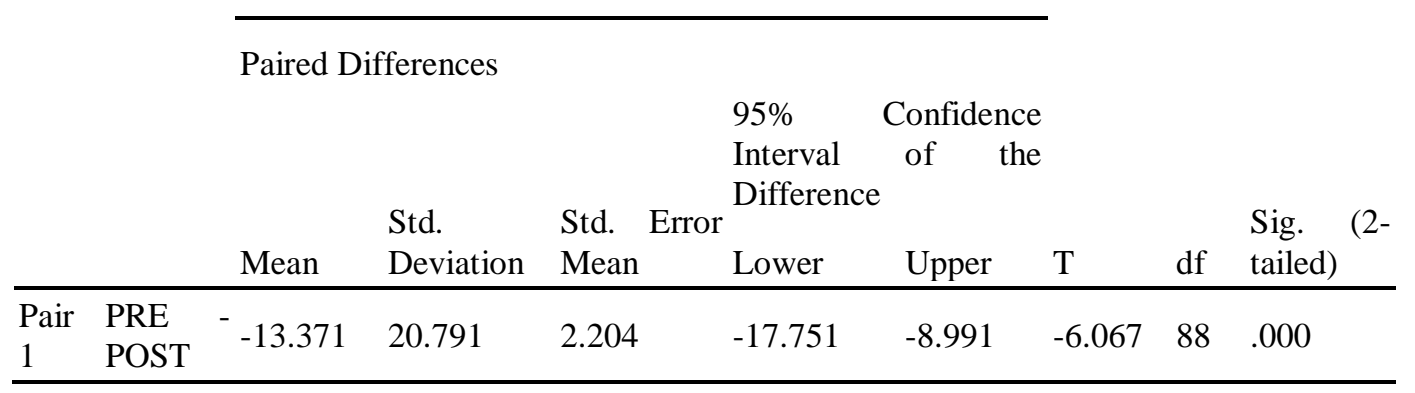

\section{Pembahasan}

Analisis data berdasarkan data yang diperoleh dari tabel 1 menunjukkan bahwa sebelum seminar pengetahuan perawat tentang manajemen nyeri dapat dilihat bahwa Perawat PK I dengan nilai $61 \%$, PK II dengan nilai $63 \%$, PK III dengan nilai $60 \%$ termasuk kategori cukup menurut Skala Pengetahuan UNAI 2015. Sedangkan PK IV dengan nilai 57\% termasuk kategori hampir cukup.

Tingkat pengetahuan perawat yang kurang dapat menyebabakan komplikasi dan keluhan yang membahayakan bagi pasien sehingga dapat menyebabkan kematian (Nasrulloh, 2009). Oleh karena nyeri bersifat subjektif, maka perawat harus peka terhadap sensasi nyeri yang dialami pasien (Asmadi, 2008). Namun sayangnya belum banyak yang diketahui dan belum dikelola dengan baik, padahal perawat memiliki lebih banyak kesempatan dibandingkan tenaga kesehatan lain untuk membantu menghilangkan nyeri dan efeknya yang membahayakan (Brunner \& Studdarth, 2010). Menurut penelitian Elysabeth dkk (2015), masih ditemukannya intervensi keperawatan yang berdasarkan "kebiasaan". Perawat harus secara sistemastis menggunakan bukti-bukti terbaik yang aktual dalam membuat keputusan mengenai cara menangani pasien.
Tindakan perawat membantu meredakan nyeri dengan memberikan intervensi penghilang nyeri (termasuk pendekatan farmakologis dan nonfarmakologis), mengkaji keefektifan intervensi tersebut, memantau terhadap efek yang merugikan dan berperan sebagai advokat pasien apabila intervensi yang dianjurkan tidak efektif dalam meredakan nyeri (Brunner \& Suddarth, 2002).

Penanganan nyeri yang dapat diberikan perawat terdiri dari tindakan farmakologis dan non farmakologis yang dijelaskan sebagai berikut: Tindakan Farmakologis: Umumnya nyeri direduksi dengan cara pemberian terapi farmakologi. Nyeri ditanggulangi dengan cara memblokade transmisi stimulan nyeri agar terjadi perubahan persepsi dan dengan mengurangi respon kortikal terhadap nyeri.1) Adapun obat yang digunakan untuk terapi nyeri adalah: Analgesik Narkotik, analgesic lokal, analgesic yang dikontrol klien, obat-obatan nonsteroid. Tindakan Non Farmakologis: Penanganan fisik/stimulasi fisik, Stimulasi kulit, Stimulasi electric (TENS), Akupuntur, Plasebo, Intervensi perilaku kognitif. Tujuan dari intervensi ini adalah menolong klien untuk mengontrol rasa nyeri secara keseluruhan. Beberapa jenis CBI yaitu: Relaksasi, Umpan balik biologis, Hipnotis/Reframing, Distraksi, dan Guided 
Imagery (Imajinasi terbimbing) (DeLaune \& Ladner, 2011).

Kesalahpahaman tentang nyeri dan manajemen umumnya terjadi pada penyedia layanan kesehatan dan pasien, diantaranya adalah 1) Nyeri adalah akibat, bukan penyebab. Menurut pandangan konvensional tentang nyeri, nyeri adalah gejala, bukan kondisi. Nyeri saat ini dikenal memiliki efek yang segera dan jangka panjang, seperti imobilitas, marah, dan ansietas; nyeri juga dapat menunda penyembuhan dan rehabilitas. 2) Nyeri kronis benar-benar jenis depresi yang tersembunyi. Serotonin berperan sebagai zat kimia dalam penyebaran nyeri dan juga merupakan modulator depresi utama. Oleh sebab itu, nyeri dan depresi secara kimia berkaitan, bukan eksklusif satu sama lain. Nyeri juga biasa ditemukan berdampingan. 3) Obat narkotik sangat berisiko digunakan pada nyeri kronis. Kesalahpahaman yang umum terjadi ini sering menghilangkan sumber pereda nyeri yang paling efektif pada pasien. Analgesic opioid (narkotik) saat ini dikenal sebagai strategi yang tepat untuk menangani nyeri kronis yang tidak sembuh dengan strategi lain. 4) Cara terbaik adalah menunggu hingga pasien mengalami nyeri sebelum memberikan medikasi. Meredakan nyeri sebelum nyeri itu bertambah parah secara umum dipahami karena memiliki efek yang mudah dilihat terkait seberapa nyeri yang pasien alami. 5) Banyak pasien yang berbohonh terhadap adanya atau tingkat keparahan nyeri yang mereka alami. Sangat sedikit pasien berbohong mengenai nyeri mereka. 6) Pereda nyeri berbeda dengan diagnosis. Manajemen nyeri yang efektif dengan menggunakan analgesik di ruang IGD dipandang tidak memiliki dampak pada temuan pengkajian fisik atau diagnosis (Pasero, 2003)

Diketahui hasil persentase sesudah dilakukan tindakan seminar pengetahuan perawat tentang manajemen nyeri pada perawat PK I dengan nilai $70 \%$, termasuk kategori lebih dari cukup menurut Skala Pengetahuan UNAI 2015, PK II dengan nilai 76\%, PK III dengan nilai 73\%, termasuk kategori cukup baik, dan PK IV dengan nilai 78 termasuk kategori baik.

Pengetahuan yang baik dari seorang perawat dapat menjadikan perawat bertindak lebih baik dalam melakukan tindakan keperawatan manajemen nyeri. Dengan pengetahuan yang baik juga perawat dapat lebih dinamis dalam menerima informasi baru yang berkaitan dengan manajemen nyeri. Latar belakang pendidikan dapat mempengaruhi motivasi seseorang dalam bertindak. Perawat yang memiliki latar belakang pendidikan yang lebih tinggi akan memiliki pengetahuan dan wawasan yang luas dibandingkan yang memiliki pendidikan yang lebih rendah. Pendidikan seseorang dapat meningkatkan kematangan intelektual sehingga dapat membuat keputusan dalam bertindak (Nursalam, 2013).

Relaksasi secara umum sebagai metode yang paling efektif terutama pada pasien yang mengalami nyeri (National Safety Council, 2003). Hasil penelitian ini didukung oleh hasil penelitian Dewi dkk (2009) yang menyimpulkan bahwa terdapat pengaruh yang signifikan pada pemberian tehnik relaksasi terhadap penurunan persepsi nyeri. Hal ini sesuai dengan teori yang diungkapkan oleh Bruner \& Suddart (2013), bahwa tehnik relaksasi napas dalam efektif untuk mengatasi nyeri, termasuk pada pasien dengan abdominal pain. Manajemen nyeri untuk mengendalikan nyeri pada pasien dengan abdominal pain yang dilakukan secara multidisiplin sangat perlu dilakukan mengingat manajemen nyeri termasuk indikator mutu pelayanan institusi rumah sakit. Pengendalian rasa nyeri pada pasien dengan abdominal pain sangat penting dalam tatanan pelayanan keperawatan.

Perawat berperan penting dalam menurunkan skala nyeri pasien dengan abdominal pain. Teori self-care dari Orem's selfcare deficit theory of nursing menjelaskan bagaimana tindakan self-care membantu individu untuk menghilangkan nyeri; 1) totally compensatory, perawat menggantikan klien dalam perawatan diri (membantu sepenuhnya), 2) partly compensatory, adalah perawat dan klien bekerja sama untuk memenuhi kebutuhan klien, dan 3) supportive-educative; klien sebagai agens self-care tetapi memerlukan bantuan dalam mengambil keputusan, modifikasi perilaku dan meningkatkan pengetahuan dan keahlian, Perawat bertindak sebagai pendukung dan pemberi pendidikan ketika menggunakan relaksasi untuk menghilangkan nyeri pada Abdominal Pain.

Berdasarkan hasil interpretasi data dengan menggunakan uji Paired t-test didapatkan 
nilai $p$ value pada perawat PK I - PK IV adalah 0,000 yang berarti signifikan lebih kecil dari tariff signifikan $5 \%$. Dengan demikian nilai $\mathrm{p}<0,05$, menunjukkan ada perbedaan yang signifikan antara pengetahuan perawat sebelum dan sesudah dilakukannya seminar atau In House Training pengetahuan perawat PK I - PK IV tentang manajemen nyeri.

Manajemen nyeri atau pain management adalah salah satu bagian dari disiplin ilmu medis yang berkaitan dengan upaya-upaya menghilangkan nyeri atau pain relief. Management nyeri ini menggunakan pendekatan multidisiplin yang didalamnya termasuk pendekatan farmakologikal (termasuk pain modifiers), non farmakologikal dan psikologikal. managemen nyeri non farmakologikal merupakan upaya-upaya mengatasi atau menghilangkan nyeri dengan menggunakan pendekatan non farmakologi. Upaya-upaya tersebut antara lain relaksasi, distraksi, massage, guided imaginary dan lain sebagainya. Teknik relaksasi merupakan intervensi keperawatan secara mandiri untuk menurunkan intensitas nyeri, Teknik relaksasi memberikan individu kontrol diri ketika terjadi rasa nyeri serta dapat digunakan pada saat seseorang sehat ataupun sakit (Perry \& Potter, 2005). Relaksasi otot skeletal dipercaya dapat menurunkan nyeri dengan merilekskan tegangan otot yang menunjang nyeri.

Ada banyak bukti yang menunjukkan bahwa relaksasi efektif dalam meredakan nyeri (Smeltzer, 2008). Penelitian manajemen nyeri yang menggunakan multidisiplin ilmu (neurologi, fisioterapi dan psikologi) yang sedang diterapkan di Indonesia adalah Program Tatalaksana Nyeri Kronis Multidisiplin (Potensi). Potensi diadaptasi dari penelitian di Rumah Sakit Selayang Malaysia (Menang) yang dikembangkan oleh Cardosa, Osman, Nicholas, Tonkin, Williams, Aziz, Ali, \& Dahari pada tahun 2012. Program Potensi ini dilakukan di Rumah Sakit Atma Jaya Jakarta sejak 2016. Program Potensi ini melibatkan dokter spesialis saraf, dokter spesialis rehabilitasi medik, terapis serta psikolog klinis dengan pendekatan Cognitive Behavior Therapy. Untuk menggunakan program Potensi, terdapat beberapa prosedur standar yang sudah ada seperti menggunakan pengukuran terkait depresi, stres, kecemasan (DASS), self-

Published by Faculty of Nursing | Universitas Klabat efficacy (PSEQ), self statement (PRSS), intensitas nyeri dan disabilitas yang diderita pasien nyeri kronis. Alat ukur ini wajib digunakan apabila ingin menggunakan program Potensi. Menurut KP sari (2017) Potensi merupakan metode manajemen nyeri (manajemen nyeri yang menggunakan multidisiplin ilmu neurologi, fisioterapi dan psikologi) yang dapat memberikan dampak paling baik terhadap kualitas hidup pasien nyeri kronis yang menjadi partisipan dalam penelitian ini.

\section{Kesimpulan}

Peran perawat dalam manajemen nyeri merupakan bagian yang penting dari perawatan. Peran yang lebih luas yaitu mendengarkan dengan penuh perhatian, mengkaji intensitas nyeri dan distress, merencanakan perawatan, memberikan edukasi tentang nyeri, meningkatkan penggunaan teknik nyeri nonfarmakologi dan mengevaluasi keefektifan obat serta berperan sebagai advocate pasien ketika intervensi untuk mengatasi nyeri menjadi tidak efektif atau ketika pasien tidak dapat berfungsi secara adekuat mengevaluasi hasil yang dicapai, menetapkan standar nyeri yang mengidentifikasi pemulihan nyeri sebagai hak pasien dan melakukan dokumentasi penilaian rasa nyeri. Sehingga diperlukan pengetahun mengimplementasikan prosedur khusus, dan pendidikan, pengkajian dan manajemen nyeri. Dengan memberikan In House Training kepada perawat dapat meningkatkan pengetahuan perawat dalam penatalaksanaan manajemen nyeri kepada pasien.

\section{Daftar Pustaka}

American Academy of Pain Management. (2009). Pain is an epidemic-A message from the director. Retrieved from www.aapainmanage,org

American Chronic Pain Association (ACPA). (2016). Resource guide to chronic pain medication and treatment. California American Chronic Pain Association, inc.

American Pain Society. (2016). Guidelines on the Management of Postoperative Pain. Journal. 
Badan Penelitian dan Pengembangan Kesehatan. (2013). Riset kesehatan dasar 2013. Kementrian Kesehatan RI.

Breivik, H., Collett, B., Ventafridda, V., Cohen, R.., \& Gallacher, D. (2006). Survey of chronic pain in Europe: prevalence, impact on daily life, and treatment. Eur J Pain, 10(4), 287-333. doi: 10.1016/j.ejpain.2005.06.009

Brunner \& Suddarth's. (2010). Textbook of medical-surgical nursing edition: 12. Philadelphia: The Point.

Cardosa, M., Osman, Z. J., Nicholas, M., Tonkin, L., Williams, A., Aziz, K. A., Ali, R. M., \& Dahari, N. M. (2012). Self - management of chronic pain malaysian patients: Effectiveness trial with 1 - year follow up. Transl Behav Med, 2(1). 30-37. doi: 10.1007/s13142- 011-0095-2

Dewi dkk.2009, Pengaruh Teknik Relaksasi Nafas Dalam Terhadap Penurunan Persepsi Nyeri pada Lansia dengan Artritis Reumatoid. Skripsi. Universitas Brawijaya. Malang.

Elysabeth, Dame dkk. (2015). Hubungan Tingkat Pendidikan Perawat dengan Kompetensi Aplikasi Evidence-Based Practice.http://jurnal.unai.edu/index.php/j sk/article/view/22 Medika

Feinberg M., Willer, R., Antonenko, O., \& John, O. P. (2012). Resource guide to chronic pain medication \& treatment. California: American Chronic Pain Association, Inc.

Gordon, A., Rashiq, S., Moulin, D. E., Clark, A. J., Beaulieu, A. D., Eisenhoffer J, Piraino
P. S., Quigley, P., Harsanyi, Z., \& Darke A. C. (2010). Buprenorphine transdermal systems for opioid therapy in patients with chronic low back pain. Pain Ress Man aq, 15(3), 169-178.

International Association for the Study of Pain (IASP). (2012). Pain. Diunduh dari http://www.iasp-pain.org.

Joyce M. Black, Jane Kokanson Hawks. (2014). Keperawatan Medikal-Bedah: Manajemen Klinis untuk Hasil yang Diharapkan, Edisi 8-Buku 1. Indonesia: Penerbit Salemba

Kuntono, HP. 2011. Nyeri Secara Umum dan Osteoarthritis dari Aspek Fisioterapi. Cet I. SurakartaL Muhammadiyah University Press.

LeMone, Priscilla, (2018). Buku Ajar Keperawatan Medikal Bedah, Ed.5 Vol.1 Penerbit Buku Kedokteran EGC

McCaffery, M. (1979). Nursing management of the patient with pain. Philadelphia: Lippincott

Nursalam. (2014). Pendidikan Keperawatan Jiwa. Yoyakarta.

Pasero, C. (2003), Pain in the emergency department. Withholding pain medication is not justified. American Journal of nursing. 103(7),73-74

Persatuan Dokter Saraf Indonesia (PERDOSSI). (2007). Penatalaksanaan nyeri. Jakarta. PERDOSSI.

Purba, J. S. (2006). Nyeri punggung bawah: Studi epidemiolog, patofisiologi, dan penanggulangan. BNS, 7(2), 85-93. 